Document downloaded from:

http://hdl.handle.net/10251/48818

This paper must be cited as:

M.D. Samper; V. Fombuena; T. Boronat; D. Garcia-Sanoguera; R. Balart (2012). Thermal and Mechanical Characterization of Epoxy Resins (ELO and ESO) Cured with Anhydrides. Journal of the American Oil Chemists' Society. 89(8):1521-1528. doi:10.1007/s11746-0122041-y.

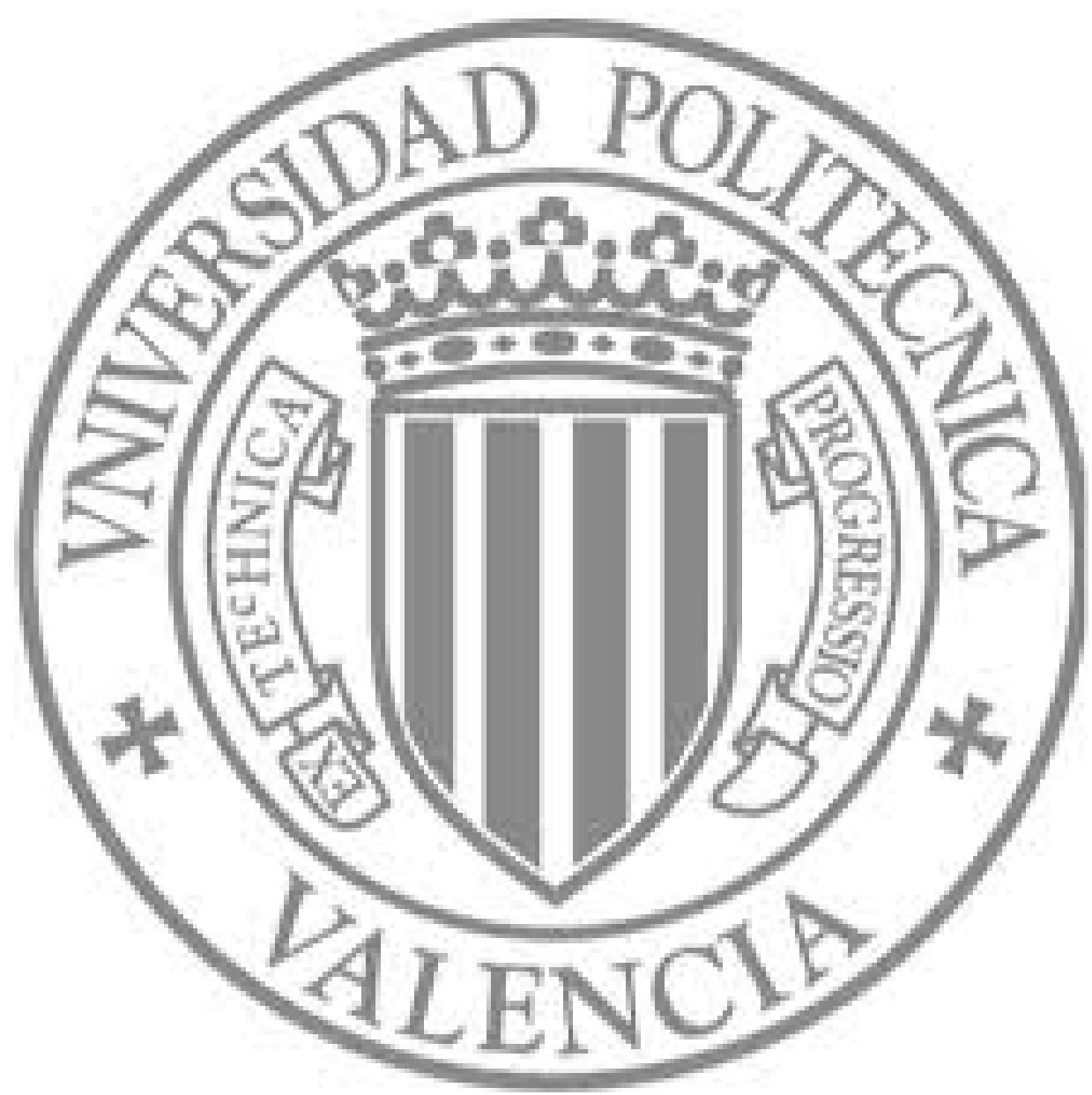

The final publication is available at

http://dx.doi.org/10.1007/s11746-012-2041-y

Copyright Springer Verlag (Germany) 


\title{
Thermal and mechanical characterization of epoxy resins (ELO and ESO) cured with anhydrides.
}

\author{
Samper M.D.*, Fombuena V., Boronat T., García-Sanoguera D. and Balart R. \\ Instituto de Tecnología de Materiales (ITM), \\ Universidad Politécnica de Valencia (UPV), \\ Plaza Ferrándiz y Carbonell s/n, 03801, Alcoy, Alicante, Spain \\ e-mail: masammad@upvnet.upv.es
}

\begin{abstract}
In this work we have developed polymeric materials from epoxidized vegetable oils in order to obtain materials with excellent mechanical properties for use as green matrix composites. Epoxidized soybean oil (ESO), epoxidized linseed oil (ELO) and different mixtures of the two oils were used to produce the polymers. Phthalic anhydride (17 mol\%) and maleic anhydride (83 mol\%) which has a eutectic reaction temperature of $48{ }^{\circ} \mathrm{C}$ were used as crosslinking agents while benzyl dimethyl amine (BDMA) and ethylene glycol were used as catalyst and initiator, respectively. The results showed that samples 100ELO and 80ELO20ESO could be used as a matrix in green composites because they demonstrated good mechanical properties
\end{abstract}

Key words: Epoxy resins, ELO, ESO, EVO, anhydrides and mechanical characterization. 


\section{INTRODUCTION}

Polymeric materials derived from renewable resources have attracted a great deal of attention in recent years, mainly due to the fact that they can reduce the environmental impact of industrial activity as they are now considered to be a viable alternative in many sectors.

Biodegradable polymers can be classified into four categories, but only the first three of these are obtained through renewable resources:

a) polymers obtained from bio-mass derived from agro-resources (eg. starch, cellulose, etc.);

b) polymers obtained from microbial production (eg. polyhydroyalkanoates (PHAs));

c) conventional polymers and those from chemical synthesis whose monomers are obtained from agro-resources (eg. polylactic acid (PLA));

d) polymers whose monomers and polymers are obtained in conventional form, through chemical synthesis.

Therefore, biodegradable polymers can be divided into two families, agro-polymers (category a), and biodegradable polyesters (categories b-d) [1]

One of the applications of biodegradable materials are their use as matrices in green composites, which are generally focused on creating a balance between profitability, respect for the environment and the characteristics of hybrid compounds.

A great deal of research has been carried out into the biodegradable thermoplastic matrices used in green composites. These materials include polylactic acid (PLA), polyhydroxybutyrate-co-hydroxyvalerate (PHB/V) and thermoplastic starch (TPS). These matrices have been mixed with different fibers and natural loads, such as shredded bamboo stem, coconut fiber, cellulose, jute, reeds, wood and talc particles with the aim of improving material properties [2] 
The most used biodegradable thermo-stable matrices in the manufacture of green composites are polyester and epoxidized and phenolic resins. Biodegradable polyester resins can be derived from isosorbide used as polyol. Isosorbide is a rigid carbohydrate obtained from starch through hydrolysis and hydrogenation of the glucose in sorbitol [3], and this resin can be used as reinforcement with linen fibers to create greater resistance, as a good interaction between fiber and matrix is produced [4]. The phenolic resins most used in biodegradable compound materials are resorcinolformaldehyde and cardanol derivatives, which are a sub-product of the processing of cashew nuts, and the materials used for reinforcement are pine needles and hibiscus and jute fibers $[5,6]$. Finally, epoxidized resins, particularly those derived from epoxidized vegetable oils (EVO) are a good alternative to reduce environmental impact as they are gained from renewable resources, they are economical, they are not noxious and they are potentially renewable.

Vegetable oils are composed of triglycerides which are liquid at room temperature. A triglyceride is an ester made up of a glycerol molecule and three fatty acids. The fatty acids make up about $94-96 \%$ of the total weight of a triglyceride molecule. Moreover, fatty acids have double bonds, $(\mathrm{C}=\mathrm{c})$, which give the opportunity to modify their chemical structure through epoxidation. The epoxidation method for oleo-chemicals has been known for many years [7], and the process can also be applied to vegetable oils [8] forming oxirane rings where previously there were double bonds between carbons. It is possible to crosslink the triglyceride chains of epoxidized vegetable oils by breaking the oxyrane ring and incorporating conventional cross-linking agents such as amines [9] and anhydrides [10] . In order that the cross-linking takes place correctly it is important to consider the Equivalent Weight both of the EVO and the cross-linking agent to indicate the stoichiometric ratio used. The Equivalent Weight is used to indicate the reactivity of the substance and is the equivalent mass of substance that contains an equivalent gram of chemical reagent and is used to define the ratio used. 
EVO can be used in the production of compound materials with the incorporation of different reinforcing agents, such as linen fiber or cellulose fiber.

In this work, polymeric materials were developed from epoxidized vegetable oils and these materials were then used as matrices in compound materials. To be more precise, the materials used were epoxidized soya oil (ESO), epoxidized linseed oil (ELO), and different mixtures of both oils to obtain optimum matrices with a good balance in terms of thermal and mechanical properties. As a cross-linking agent a mixture of maleic anhydride and phthalic anhydride were used. The initiator used was ethylene glycol which acts as an opener for the cross-linking agents (maleic anhydride and phthalic anhydride), generating two hydroxyl groups which link the EVO chains. Finally, benzyl dimethyl amine was used as a catalyst to accelerate the reaction.

\section{EXPERIMENTAL}

\section{Materials and preparation of samples}

To obtain the biodegradable materials, commercial grade ELO was used with an EEW (Equivalent Epoxide Weight) of 178 along with commercial grade ESO with an EEW of 238. Both of these resins were supplied by Traquisa S.A. (Madrid, Spain). As a crosslinking agent, a mixture of phthalic anhydride (PA) which has a melting temperature of $131.8 \stackrel{\circ}{\circ}$, and an EAW (Equivalent Anhydride Weight) of 148 , and maleic anhydride (MA) whose melting temperature is $54.4^{\circ} \mathrm{C}$, with an EAW of 98 were used. This system (PA/MA) shows a eutectic transformation reaction at $48.33^{\circ} \mathrm{C}$, which enables curing processes at lower temperatures than individual anhydrides. Fig. 1 shows the calorimetric graph of PA, MA and the mixture of both. The graph clearly shows that the PA/MA mixture has a lower melting point than the individual materials. The phthalic anhydride was 99\% pure and was supplied by Acros Orgánica (Geel, Belgium) and the maleic anhydride was $98 \%$ pure and was supplied by Sigma-Aldrich (Schnelldorf, Germany). As an initiator, extra-pure ethylene glycol was used which was supplied by 
Scharlau (Sentmenat, Spain), and finally, 99\% pure benzyl dimethyl amine (BDMA) was used as a catalyst/accelerator. This was supplied by Acros Organics.

The samples were prepared with a stoichiometric relationship, $R$, of $0.8(R=$ anhydride equiv/epoxy equiv = anhydride groups/epoxy groups). It was decided to use this stoichiometric relationship because in other studies it has been seen that the reaction enthalpy remains fairly stable up to $R=0.8[11]$.

The samples were prepared by mixing PA $(23.8 \%$ by weight) and MA $(76.2 \%$ by weight) at $60^{\circ} \mathrm{C}$ with a magnetic stirrer to the melt the PA/MA. The epoxidized oil was manually mixed with BDMA $(1.5 \%)[12,13]$ and ethylene glycol (1\%) [14] and was oven-tempered at $60^{\circ} \mathrm{C}$ to mix all the components and so that the PA/MA did not solidify. When the anhydride mixture had melted, the oil mixture was added and the entire mixture was magnetically stirred for 3 minutes. The mixture was then placed in a silicon mold at $60^{\circ} \mathrm{C}$ and placed in a fan oven (Carbolite model) made by (Productos Keison, Barcelona, Spain). The percentages of epoxidized oil of the different samples and the differerent curing cycles (optimized in previous studies) can be seen in Table 1. Test pieces of around 3-4 mm were obtained which were used for flexural and impact tests.

\section{$\underline{\text { Thermal characterization }}$}

The calorimetric analysis was carried out using Mettler-Toledo 821 DSC equipment (Mettler-Toledo, Schwerzenbach, Switzerland). The samples used had a weight of between 4 and $6 \mathrm{mg}$. The uncured samples were heated from $45^{\circ} \mathrm{C}$ up to $300{ }^{\circ} \mathrm{C}$ at a rate of $5^{\circ} \mathrm{C} \min ^{-1}$.

The curing process of the anhydride system can be clearly identified as an exothermic peak between $146.38^{\circ} \mathrm{C}$ and $150.97^{\circ} \mathrm{C}$. The reaction enthalpy has been calculated through determining the total peak area related to total sample weight and this parameter is representative for crosslinking curing extent.

\section{Mechanical characterization}


The mechanical characterization was carried out using flexural, hardness and impact tests.

The flexural tests were carried out using a universal ELIB 30 (S.A.E. Ibertest, Madrid, Spain) applying the standard ISO 178. All the tests were carried out at room temperature at a speed of $5 \mathrm{~mm} \mathrm{~min}^{-1}$ and with a load cell of $5 \mathrm{KN}$. At least 5 test pieces of each sample were used and the values for the flexural modulus, maximum deflection and flexural strength were determined as the average of the 5 values.

The hardness tests were carried out using a shore D durometer, as indicated in the norm UNE-EN ISO 868. The equipment used was a mod. 673-D durometer (Instrumentos J. Bot S.A., Barcelona, Spain) using samples of $4 \mathrm{~mm}$ thickness. A minimum of 5 measurements were taken and the average values were calculated.

The impact tests were done using a Metrotec test machine with a $6 \mathrm{~J}$ pendulum. The test pieces were "V" notched at $45^{\circ}$ with a notch radius of $0.25 \mathrm{~mm}$ according to the norm ISO 179:1993.

The characterization of the fracture surface was carried out using a scanning electron microscope (SEM), Phenom ${ }^{\mathrm{TM}}$ (FEI company, Eindhoven, Nederland). The samples were covered in a layer of gold under vacuum conditions.

\section{Thermo-mechanical characterization}

The thermo-mechanical analysis was carried out using TMA equipment made by TA Instruments, model Q400 (New Castle, Delaware, USA). The samples used had a diameter of $7 \mathrm{~mm}$ and a thickness of $4 \mathrm{~mm}$. The expansion method was used with a heating temperature from $0 \stackrel{\circ}{\circ} \mathrm{C}$ up to $140 \stackrel{\circ}{\circ} \mathrm{C}$ at $5{ }^{\circ} \mathrm{C} \min ^{-1}$ with a weight of $0,02 \mathrm{~N}$. All the tests were carried out in a nitrogen atmosphere.

The Heat Deflection Temperature was also determined by applying procedure $B$ of the norm UNE EN ISO 75 which recommends the use of $0,45 \mathrm{MPa}$ of load, and to carry out 
the test at $120^{\circ} \mathrm{C} \mathrm{h}^{-1}$. The VICAT softening temperature was determined using the B50 method described in the norm UNE EN ISO 306, which recommends the use of a $50 \mathrm{~N}$ load and a heating rate of $50{ }^{\circ} \mathrm{Ch}^{-1}$.

\section{RESULTS}

Curing the resin is the most important step to obtain samples with good properties, as the cross-linking of the resins takes place during this phase. The curing cycle of the different samples were evaluated using differential scanning calorimetry (DSC). The calorimetric curves shown in Fig. 2 show that as the quantity of ESO in the (ESO/ELO:PA/MA) system is increased the reaction enthalpy decreases due to the fact that the ESO has less epoxy groups in its structure and fewer cross-linking bonds are produced than in the ELO. However, the sample that contains $20 \%$ ELO and $80 \%$ ESO is the one that shows the least reaction enthalpy, $12.96 \mathrm{~J} \mathrm{~g}^{-1}$, and this fact explains why this sample does not cure well and why there are sticky areas on the surface of the sample. The reaction peak temperature and the process enthalpy are shown in Table 2. The peak temperature represents the temperature at which the greatest cross-linking rate takes place. There is not much variation in this over all the samples and it falls between 146.38 and $150.97^{\circ} \mathrm{C}$.

The enthalpy process has been calculated by determining the total peak area related to total sample weight and this parameter is representative for crosslinking curing extent. Fig. 2 shows that the reaction enthalpy began between 100 to $125^{\circ} \mathrm{C}$ and ended between 165 to $185^{\circ} \mathrm{C}$, depending on the sample.

The crosslinking process is exothermic as observed in the DSC curves. We can clearly observe that exothermicity reaches maximum values for ELO cured with the eutectic anhydride mixture and lower exothermicity values are obtained with increasing ESO content. This is in accordance with the chemical structure of the vegetable oils. As we have described in the experimental section ELO is characterized by an EEW of 178 while ESO possesses an EEW of 238. This means that ELO contains more epoxy 
groups per molecule than ESO, so that, ELO curing leads to higher exothermicity as more epoxy groups can react.

The data obtained in the flexural tests show that as the quantity of ESO in the system is increased, the flexural strength and flexural modulus decrease. These results can be seen in Fig. 3, and it is worth highlighting that the 100 ELO system shows a strength of 35.8 MPa and a flexural modulus of $622.8 \mathrm{MPa}$, and that when the percentage of ESO is increased to $20 \%$ the strength decreases slightly $(33.4 \mathrm{MPa})$ and the flexural modulus increases $(676.4 \mathrm{MPa})$. This increase is very low and may be due to a variation in results. Above this percentage an increase in the quantity of ESO causes a sharp decrease in both properties until values of $1.3 \mathrm{MPa}$ in Strength and of $11.1 \mathrm{MPa}$ in flexural modulus for the 100ESO sample are reached. This behavior is due to the fact that the ESO shows less cross-linking between the chains as its structure has less epoxy groups than the ELO, allowing more slippage of the chains and increasing the ductile characteristics.

The hardness and impact properties are reflected in Fig. 4. Here we can see that the Shore $D$ hardness decreases as the quantity of ESO in the system increases, from a Shore D of 66.5 in the case of 100ELO, up to 21.9 Shore $D$ in the case of 100ESO. On the other hand, the impact energy of the samples increases as the ESO content increases, from $4.2 \mathrm{KJ} \cdot \mathrm{m}^{-2}$ in the case of $100 \mathrm{ELO}$ up to $6.9 \mathrm{KJ} \cdot \mathrm{m}^{-2}$ in the case of 100ESO. This behavior is related to the structure of the material, and as we have previously seen, is due to the quantity of links in the cross-linking that exists in the different materials. The ELO shows more epoxy groups in its structure than the ESO, and the materials with a greater quantity of ELO show more cross-linking points between the chains, thus the material is more rigid. As the percentage of ELO decreases, there is less cross-linking and the chains are more likely to slide and thus the material is more ductile. 
The morphological analysis through SEM of the fracture surface of the samples submitted to impacts shows that the fracture of 100ELO material has a smooth homogeneous surface (Fig. Figure 5.a), which is characteristic of polymer materials or thermo-stable resins that show fragile fractures. The sample 80ELO20ESO also displays a smooth surface, although some small crests do appear (Fig. 5Figure .b). Fig. 5.c shows the micrographs of the sample 60ELO40ESO, and in this it is possible to observe crests formed in the direction of the break in the material. As the ESO content of the mixture is increased (Fig. 5.d, Fig. 5.e, and Fig. 5.f) it was observed that the crests increased in both size and number. This is related to the mechanical behavior analyzed previously - the 100ELO and 80ELO20ESO samples have greater resistance and the fracture surface is smooth, which is a characteristic of fragile, thermo-stable polymer materials. As we have previously described, ESO is characterized by lower content of epoxy groups in comparison to ELO. This means that crosslinking density with ESO is lower than that obtained with individual ELO. The crosslinking density is directly related to material stiffness. High stiffness values are obtained for systems with high crosslinking density and this fact restricts deformation mechanisms. In contrast, low crosslinking densities lead to lower stiffness values, which indicate that some chain mobility can occur due to presence of less interlocking points, so that more ductile properties can be achieved. This behavior is clearly seen in the ELO:ESO system as more ductile properties are obtained by increasing ESO content.

Analysis of the thermo-mechanical behavior allows us to obtain, among other parameters, the glass transition temperature $(\mathrm{Tg})$ of the different materials in order to ascertain if there are any differences between them.

The $\mathrm{Tg}$ can be seen in the TMA technique as a change in the slope of the curve. The results shown in Table 3 show that the $\mathrm{Tg}$ falls from $37.10^{\circ} \mathrm{C}$ in sample 100 ELO (Fig.6.a), to $26.96{ }^{\circ} \mathrm{C}$ in the sample 100ESO (Fig.6.b), and therefore, the increase in the percentage of ESO in the mixture causes a reduction in this property, the same as 
can be seen in the mechanical flexural properties of the system, as once again, as the percentage of ESO in the system is increased the system becomes more ductile. Both the reduction in the $\mathrm{Tg}$ and the increase in ductility are related to the increase in the percentage of ESO in the mixture due to the internal structure of this material, given that the ESO has less epoxy groups in its structure and when cross-linking takes place, the chains have more space to move around.

The linear thermal expansion coefficients (LTEC) is the slope of the line is represented by the dimension change and temperature (TMA graph). The LTEC were calculated before and after the $\mathrm{Tg}$, as the slope of the straight line is different. Table 3 shows that the LTEC calculated before the $\mathrm{Tg}$ increases from $1.24 \cdot 10^{-4}{ }^{\circ} \mathrm{C}^{-1}$ in the sample 100ELO, up to $1,75 \cdot 10^{-4}{ }^{\circ} \mathrm{C}^{-1}$ in the sample 100ESO. This data shows that the samples with higher ESO content expand less. Moreover, the LTEC calculated after the $\mathrm{Tg}$ shows the same behavior, but it is worth highlighting that the value is higher and that this is due to the fact that above this temperature the polymer chains have more energy which allows them to move more and expand more when the temperature is below the $\operatorname{Tg}$.

Fig. 7 shows that as the percentage of ESO is increased, the VICAT softening temperature and the heat deflection temperature decrease, and the drop in these values is due, as has been previously seen, to the structure of the material, and that the samples with a high percentage of ELO are more cross-linked than the samples with a higher percentage of ESO. In the case of the HDT method A (1.8 MPa, $120^{\circ} \mathrm{C}^{-}$ ${ }^{1}$ ) was used first, but as samples 40ELO60ESO, 20ELO80ESO and 100ESO showed HDT below room temperature, the tests were carried out using method B (0.45 MPA, $\left.120{ }^{\circ} \mathrm{C} \mathrm{h}^{-1}\right)$. In the graph, the values for the ESO samples are missing. This is due to the fact that the values were lower than room temperature. 


\section{CONCLUSIONS}

Our results show that the phthalic and maleic anhyride mixtures can be used as a cross-linking agent.

The mechanical characterization shows that as the quantity of ESO in the system increases, the flexural strength and the flexural modulus decrease due to fact that there are less epoxy groups, and that the samples 100ELO and 80ELO20ESO have good mechanical properties.

Concerning the thermo-mechanical characterization, the VICAT softening temperature and the temperature of deflection under load show decreasing values as the quantity of ELO in the mixture increases, finally reaching values that are below room temperature in the case of sample 100ESO, and concerning the TMA we saw that the Tg decreases and the linear expansion coefficients increase as the quantity of ESO in the system increases.

Therefore, the properties shown by samples 100ELO (24.47 $\mathrm{g}$ MA/PA) and 80ELO20ESO (25.54 g MA/PA) mean that they could be ideal for use a matrix in green composites. However, future studies are necessary to evaluate the adherence of these resins with natural fibers, which would further improve the performance of the possible compound materials.

\section{ACKNOWLEDGEMENTS}

This work is part of the project IPT-310000-2010-037,"ECOTEXCOMP: Research and development of textile structures useful as reinforcement of composite materials with marked ecological character" funded by the "Ministerio de Ciencia e Innovacion", with an aid of 189540.20 euros, within the "Plan Nacional de Investigación Científica, Desarrollo e Innovación Tecnológica 2008-2011" and funded by the European Union 
through FEDER funds, Technology Fund 2007-2013, Operational Programme on $\mathrm{R}+\mathrm{D}+\mathrm{i}$ for and on behalf of the companies." 


\section{REFERENCES}

1. Averous $L$ (2004) Biodegradable multiphase systems based on plasticized starch: A review. J. Macromol. Sci.-Polym. Rev C44:231-274.

2. Bledzki AK,Jaszkiewicz A (2010) Mechanical performance of biocomposites based on PLA and PHBV reinforced with natural fibres - A comparative study to PP. Compos. Sci. Technol. 70:1687-1696.

3. Raquez JM, Deleglise M, Lacrampe MF,Krawczak P (2010) Thermosetting (bio)materials derived from renewable resources: A critical review. Prog. Polym. Sci. 35:487-509.

4. Charlet K, Jernot JP, Gomina M, Bizet L,Breard J (2010) Mechanical Properties of Flax Fibers and of the Derived Unidirectional Composites. J. Compos Mater. 44:28872896.

5. Barreto ACH, Esmeraldo MA, Rosa DS, Fechine PBA,Mazzetto SE (2010) Cardanol Biocomposites Reinforced with Jute Fiber: Microstructure, Biodegradability, and Mechanical Properties. Polym. Compos. 31:1928-1937.

6. Thakur VK,Singha AS (2010) Physico-chemical and Mechanical Characterization of Natural Fibre Reinforced Polymer Composites. Iran. Polym. J. 19:3-16.

7. Schmitz WR,Wallace JG (1954) Epoxidation of methyl oleate witn hydrogen peroxide. J. Am. Oil Chem. Soc. 31:363-365.

8. La Scala J,Wool RP (2002) Effect of FA composition on epoxidation kinetics of TAG. J. Am. Oil Chem. Soc. 79:373-378.

9. de Espinosa LM, Ronda JC, Galia M,Cadiz V (2008) A New Enone-Containing Triglyceride Derivative as Precursor of Thermosets from Renewable Resources. J. Polym. Sci. Pol. Chem. 46:6843-6850.

10. Gerbase AE, Petzhold CL,Costa APO (2002) Dynamic mechanical and thermal behavior of epoxy resins based on soybean oil. J. Am. Oil Chem. Soc. 79:797-802.

11. Boquillon N,Fringant C (2000) Polymer networks derived from curing of epoxidised linseed oil: influence of different catalysts and anhydride hardeners. Polymer 41:8603-8613.

12. Montserrat S, Flaque C, Calafell M, Andreu G,Malek J (1995) Influence of the accelerator concentration on the curing reaction of an epoxy-anhydride system. Thermochim. Acta 269:213-229.

13. Zacharuk M, Becker D, Coelho LAF,Pezzin SH (2011) Study of the Reaction Between Polyethylene Glycol and Epoxy Resins Using N,N-dimethylbenzylamine as Catalyst. Polimeros 21:73-77.

14. Lozada Z, Suppes GJ, Tu YC,Hsieh FH (2009) Soy-Based Polyols from Oxirane Ring Opening by Alcoholysis Reaction. J. Appl. Polym. Sci. 113:2552-2560. 


\section{Figures and Tables}

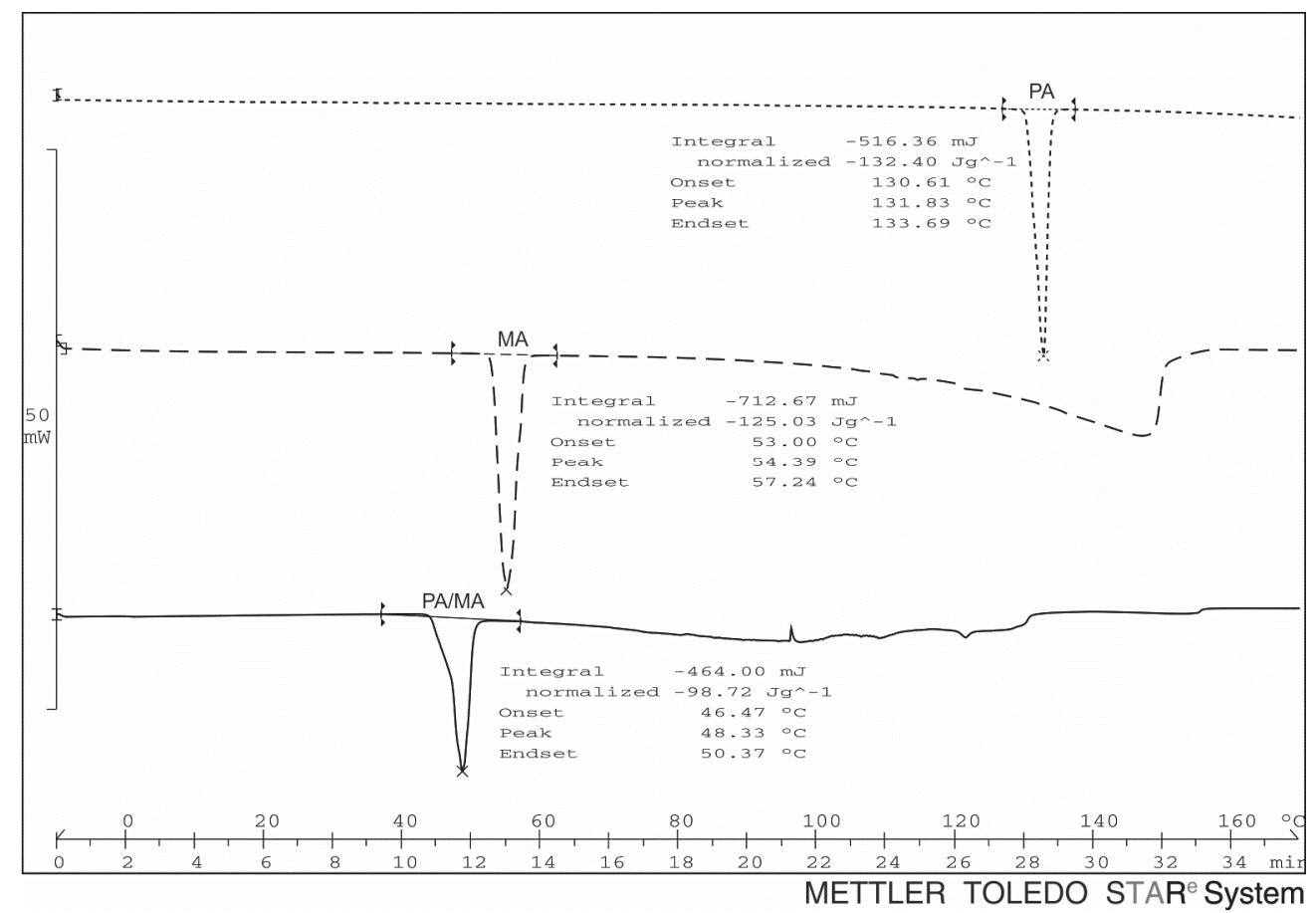

Figure 1. Calorimetric graph of the PA and MA anhydrides and a mixture of both. 


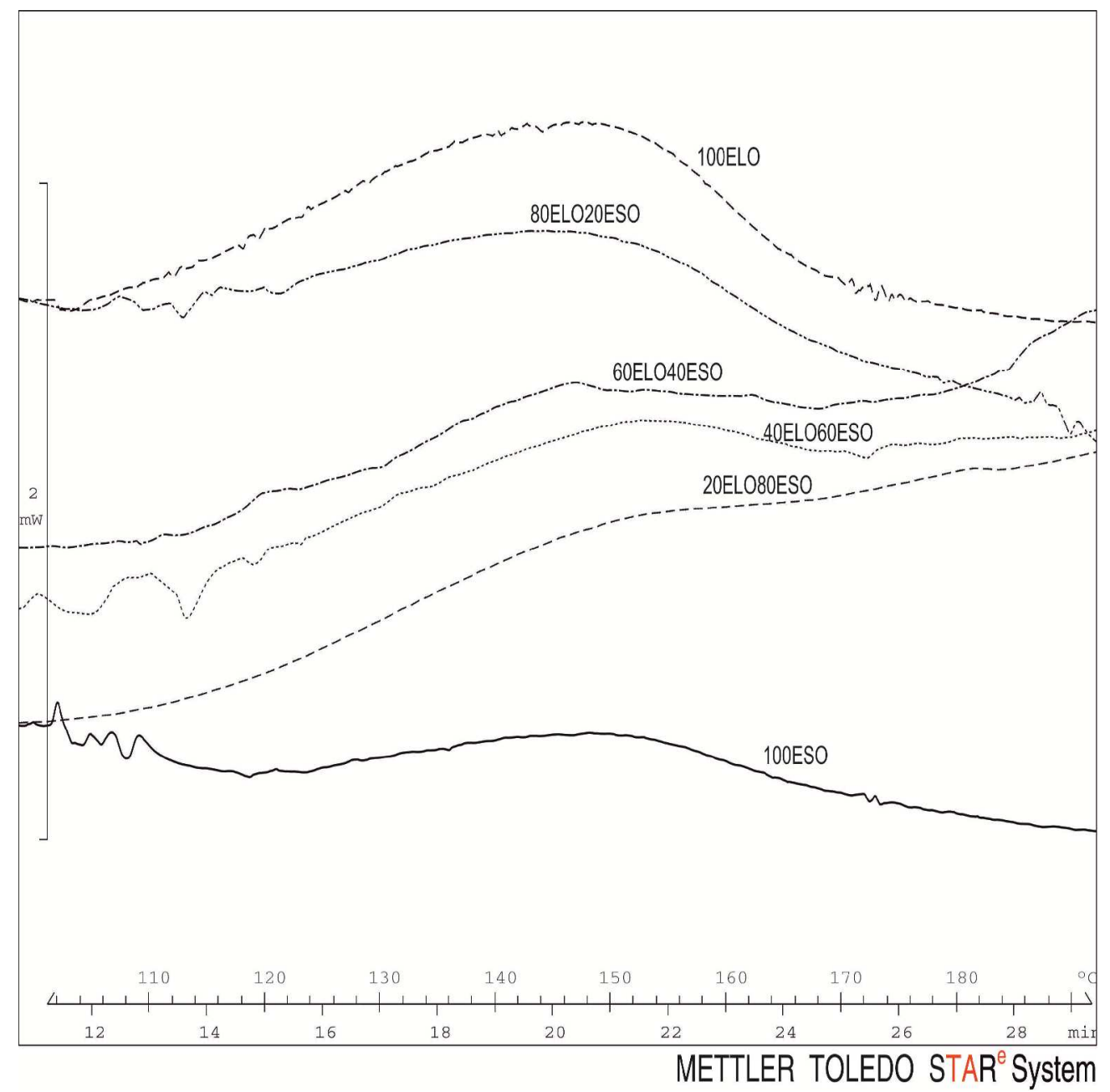

Figure 2. Graph showing DSC comparison between the different ELO-ESO mixtures.

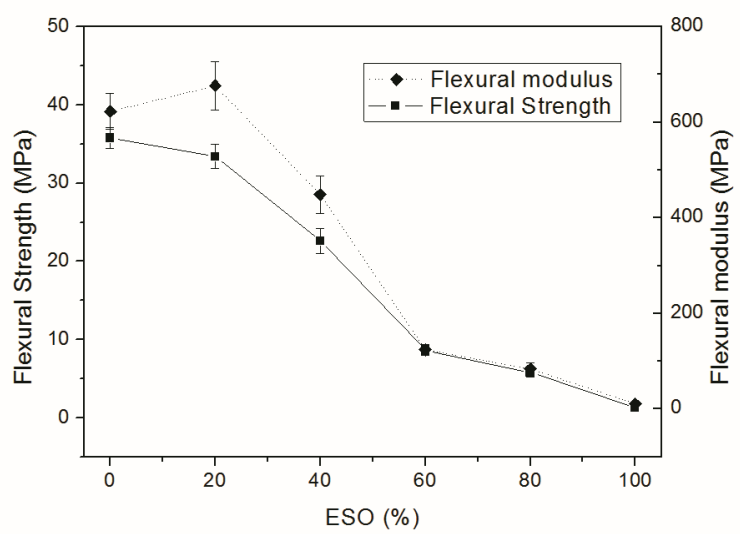

Figure 3. Comparative graph of the flexural properties of the different ELO-ESO mixtures. 


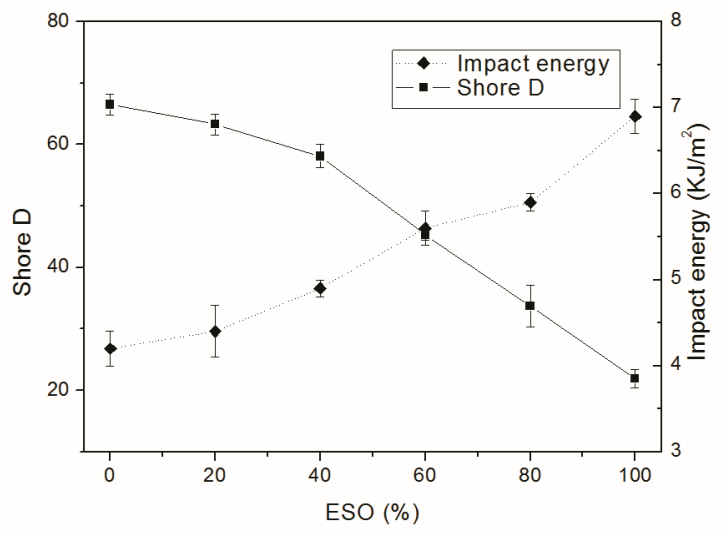

Figure 4. Comparative graph of hardness and impact values for the different ELO-ESO mixtures.
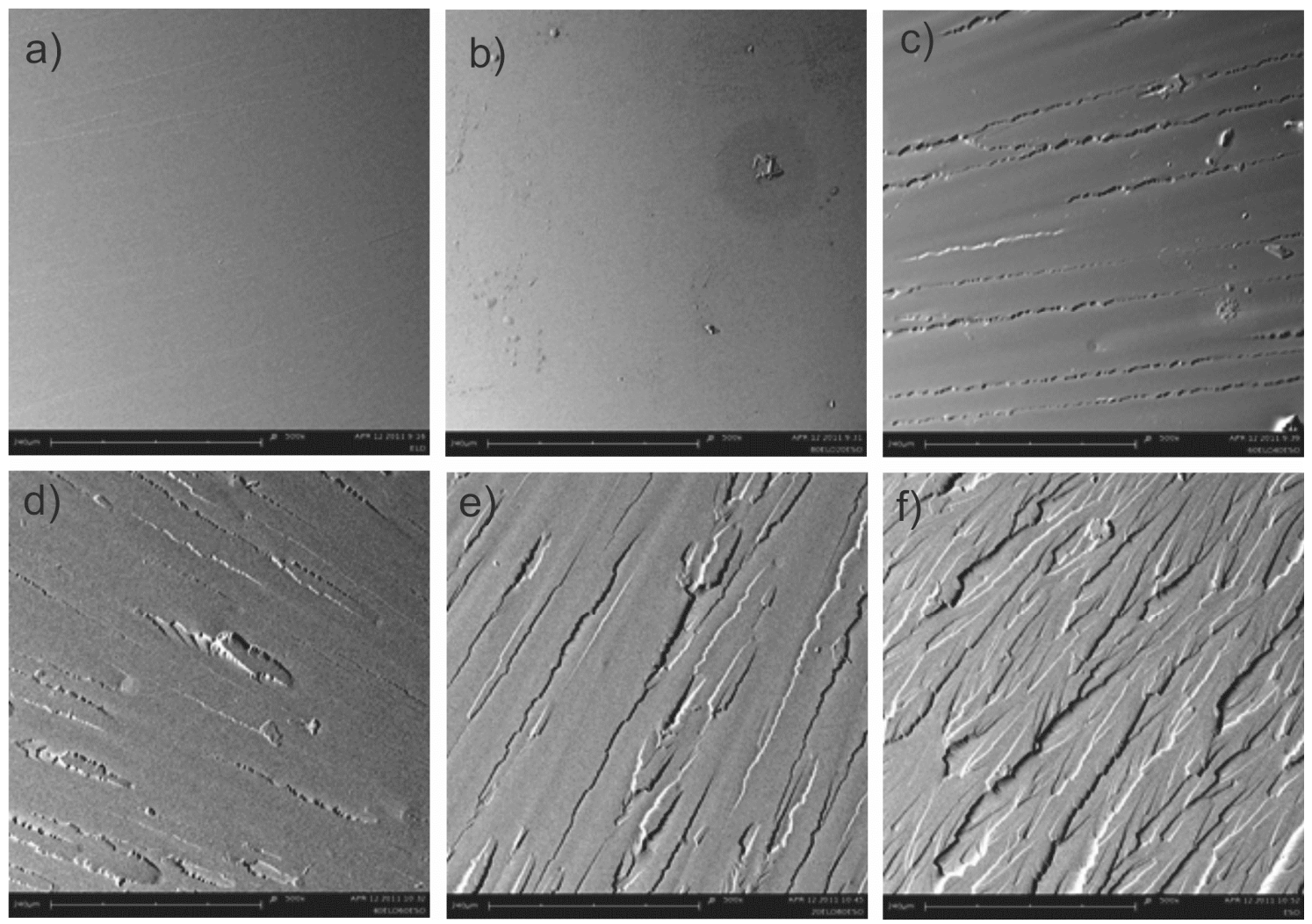

Figure 5. Microphotographs SEM at $\times 500$ of the samples a) 100ELO; b) $80 E L O 20 E S O$; c) 60ELO40ESO; d) 40ELO60ESO, e) 20ELO80ESO, f) 100ESO. 


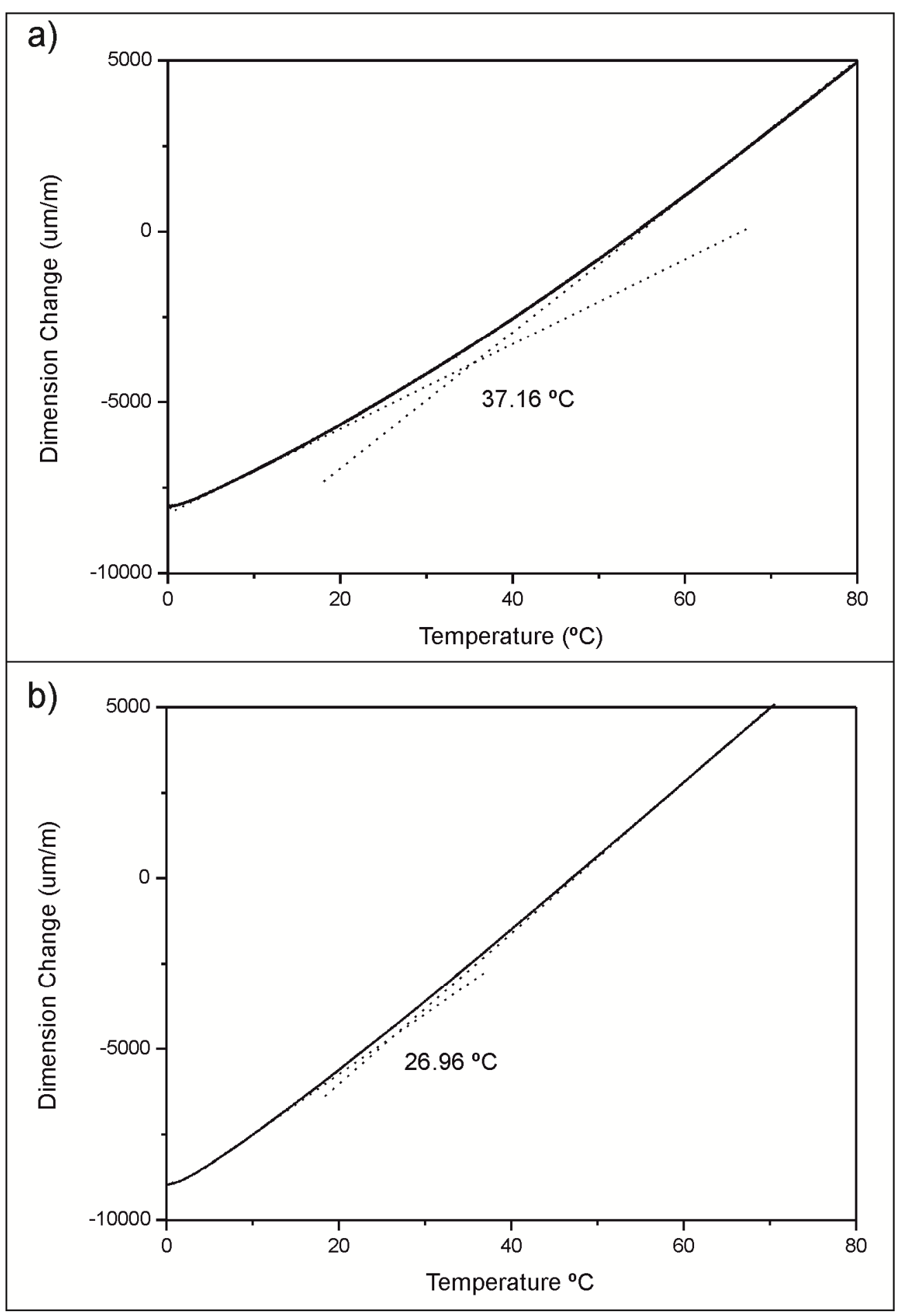

Figure 6. TMA curves: a) sample 100ELO and b) sample 100ESO 


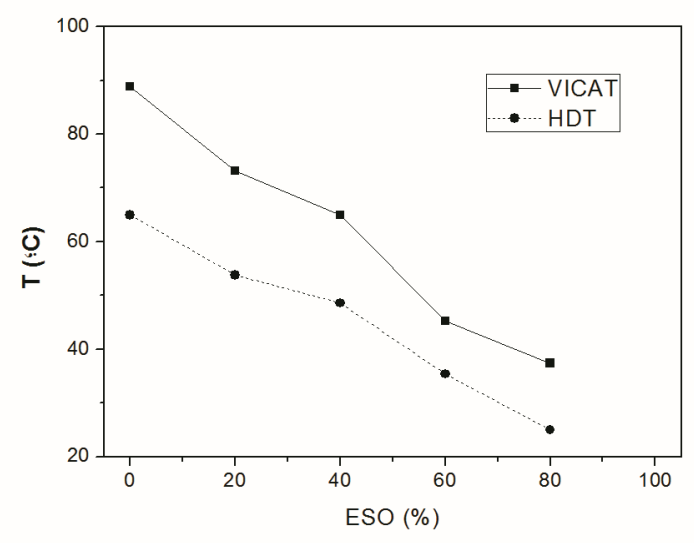

Figure 7. Comparative graph for the different ELO-ESO mixtures.

Table 1. Percentages of oils and curing conditions used in the different samples.

\begin{tabular}{|c|c|c|c|c|c|c|}
\hline Sample & $\%$ ELO & $\%$ ESO & $\begin{array}{c}\text { ELO/ESO } \\
(\mathrm{g})\end{array}$ & $\begin{array}{c}\mathrm{PA} / \mathrm{MA} \\
(\mathrm{g})\end{array}$ & $\begin{array}{c}\text { Curing } \\
\text { conditions }\end{array}$ & $\begin{array}{l}\text { Post-curing } \\
\text { conditions }\end{array}$ \\
\hline 100ELO & 100 & 0 & 51.09 & 24.47 & $90^{\circ} \mathrm{C}, 90 \mathrm{~min}$ & $160^{\circ} \mathrm{C}, 60 \mathrm{~min}$ \\
\hline 80ELO20ESO & 80 & 20 & 52.00 & 23.54 & $\begin{array}{l}90^{\circ} \mathrm{C}, 90 \mathrm{~min} \\
95^{\circ} \mathrm{C}, 60 \mathrm{~min}\end{array}$ & $160^{\circ} \mathrm{C}, 60 \mathrm{~min}$ \\
\hline 60ELO40ESO & 60 & 40 & 52.90 & 22.08 & $\begin{array}{c}105^{\circ} \mathrm{C}, 30 \\
\min \end{array}$ & $160^{\circ} \mathrm{C}, 60 \mathrm{~min}$ \\
\hline 40ELO60ESO & 40 & 60 & 53.82 & 21.20 & $\begin{array}{l}97^{\circ} \mathrm{C}, 45 \mathrm{~min} \\
105^{\circ} \mathrm{C}, 60 \mathrm{~min}\end{array}$ & $160^{\circ} \mathrm{C}, 60 \mathrm{~min}$ \\
\hline 20ELO80ESO & 20 & 80 & 54.73 & 20.83 & $\begin{array}{c}110^{\circ} \mathrm{C}, 30 \\
\min \\
115^{\circ} \mathrm{C}, 45 \\
\min \end{array}$ & $160^{\circ} \mathrm{C}, 60 \mathrm{~min}$ \\
\hline 100ESO & 0 & 100 & 55.63 & 19.93 & $105^{\circ} \mathrm{C}, 90 \mathrm{~min}$ & $160^{\circ} \mathrm{C}, 60 \mathrm{~min}$ \\
\hline
\end{tabular}


Table 2. Dynamic characteristics of the curing process of the ELO-ESO system, reaction enthalpy and peak temperature.

\begin{tabular}{lcc}
\hline \multicolumn{1}{c}{ Sample } & Peak & Enthalpy $\left(\mathrm{J} \mathrm{g}^{-1}\right)$ \\
& temperature $\left({ }^{\circ} \mathrm{C}\right)$ & \\
\hline 100ELO & 147.75 & 50.64 \\
80ELO20ESO & 147.83 & 36.04 \\
60ELO40ESO & 146.38 & 17.52 \\
40ELO60ESO & 150.97 & 15.26 \\
20ELO80ESO & 149.59 & 12.96 \\
100ESO & 149.89 & 14.50 \\
\hline
\end{tabular}

Table 3. Tg, LTEC before and after the Tg, depending on the TMA of the different ELO/ESO mixtures

\begin{tabular}{lccc}
\hline \multicolumn{1}{c}{ Sample } & $\operatorname{Tg~}\left(^{\circ} \mathrm{C}\right)$ & $\begin{array}{c}\text { LTEC (before. Tg) } \\
\left({ }^{\circ} \mathrm{C}\right)^{-1}\end{array}$ & $\begin{array}{c}\text { LTEC (after. TG) } \\
\left({ }^{\circ} \mathrm{C}\right)^{-1}\end{array}$ \\
\hline 100ELO & 37.16 & $1.24 \cdot 10^{-4}$ & $1.98 \cdot 10^{-4}$ \\
80ELO20ESO & 33.20 & $1.42 \cdot 10^{-4}$ & $2.04 \cdot 10^{-4}$ \\
60ELO40ESO & 32.28 & $1.58 \cdot 10^{-4}$ & $2.21 \cdot 10^{-4}$ \\
40ELO60ESO & 27.68 & $1.66 \cdot 10^{-4}$ & $2.45 \cdot 10^{-4}$ \\
20ELO80ESO & 28.50 & $1.72 \cdot 10^{-4}$ & $2.93 \cdot 10^{-4}$ \\
100ESO & 26.96 & $1.75 \cdot 10^{-4}$ & $2.15 \cdot 10^{-4}$ \\
\hline
\end{tabular}

